\title{
Gerónimo de Sierra: Cincuenta años de Sociologia Política- Uruguay y América Latina
}

(SIERRA, Gerónimo de. Prólogo de Alberto Riella. Buenos Aires: CLACSO, 2017) ${ }^{1}$.

Recebido: 30-05-2017

Aprovado: 05-06-2017

Marcos Antônio da Silva ${ }^{2}$

Apesar dos avanços recentes, grande parte da realidade e do pensamento social latino-americano, principalmente a produção recente, seguem ignorados ou desconhecidos no Brasil. Neste sentido, a história, cultura e a dinâmica social e política de inúmeros países, com os quais partilhamos um passado, presente e futuro comuns, permanecem distantes da formação e da visão nacional e, embora se ouça falar, superficialmente de países como Argentina, México ou Venezuela, inúmeras outras nações, como o Uruguai, permanecem como uma terra distante, desconhecida e, quase, exótica.

Se isto ocorre no plano histórico ou cultural, tal distanciamento é aprofundado no que se refere a academia, dominada pela centralidade intelectual dos países do norte, pela presença majoritária de pensadores europeus e estadunidenses, variando sua intensidade conforme as diversas disciplinas e, principalmente, pela incorporação acrítica de visões, conceitos e escolas, geralmente descolados de nossa realidade. Neste âmbito, mesmo na área do pensamento social, a produção latino-americana segue ignorada, com raras exceções, e a elaboração, as temáticas e concepções desenvolvidas por intelectuais latino-americanos pode ser apontado como um vasto campo a ser explorado e divulgado.

Desta forma, esta obra constitui um passo fundamental, e muito instigante, para o (re) conhecimento da produção latino-americana recente e a comprovação da estatura

\footnotetext{
${ }^{1}$ Disponível em: http://biblioteca.clacso.edu.ar/clacso/se/20170922113446/Geronimo_De_Sierra.pdf

${ }^{2}$ Professor do curso de Ciências Sociais e do Programa de Pós-Graduação em Sociologia (PPGS) da Universidade Federal da Grande Dourados (UFGD). Doutor em Estudos sobre a Integração LatinoAmericana (PROLAM/USP). Membro do Laboratório Interdisciplinar de Estudos sobre a América Latina (LIAL).Email: marcossilva@ufgd.edu.br
} 
e importância da produção do sociólogo uruguaio Gerónimo de Sierra para a compreensão das sociedades latino-americanas e, principalmente, do Uruguai e do Cone Sul da América Latina. Vale destacar que Gerónimo possui vínculos acadêmicos com o Brasil, tendo atuado ou trabalhado, desde os tempos de exílio, em instituições e foi, recentemente, vice-reitor da Universidade da Integração Latino-Americana (UNILA).

A obra é parte integrante da série 'Trayectorias' da coleção Antologías del Pensamiento Social Latinoamericano y Caribeño, publicada pelo Conselho LatinoAmericano de Ciências Sociais (CLACSO).

O Conselho Latino-Americano de Ciências Sociais (CLACSO) é uma instituição não-governamental, criada em 1967 e associada a UNESCO, que reúne cerca de 394 centros de pesquisa, programas de pós-graduação ou instituições em ciências humanas e sociais de 26 países da América Latina. Além deste, também são filiadas diversas instituições de EUA, Europa, África e Ásia que se dedicam ao estudo de temas latinoamericanos $^{3}$.

Desde o seu surgimento, CLACSO se tornou um espaço de reflexão autônoma das questões latino-americanas, de desenvolvimento do pensamento social e crítico e do compromisso com a superação da pobreza e desigualdade, através da construção de um caminho alternativo próprio. Neste sentido, as coleções produzidas realçam a importância de CLACSO para a construção e difusão do pensamento latino-americano ${ }^{4}$, procurando incentivar a produção própria, a compreensão autônoma e a construção de um caminho latino-americano para o desenvolvimento das ciências e, principalmente, das sociedades latino-americanas.

Além disto, tal entidade tem realizado uma intensa campanha para o acesso aberto ao conhecimento, disponibilizando em seu portal, grande parte da produção mencionada e das publicações de seus grupos de trabalho, de seus concursos e de seus centros afiliados.

Como já apontamos, a obra pertence a coleção Antologías del Pensamiento Social Latinoamericano y Caribeño, que é composta por diversos livros fundamentais para compreender o pensamento social latino-americano e caribenho, clássico e

\footnotetext{
${ }^{3}$ Para maiores informações sobre CLACSO, suas atividades, publicações e oportunidades ver o seguinte sítio: http://www.clacso.org.ar

${ }^{4} \mathrm{O}$ Brasil possui, até o momento, cerca de 51 instituições, programas de pós-graduação ou centros de pesquisa filiados.
} 
contemporâneo, organizados em cinco séries: Trayectorias, Países, Pensamientos Silenciados, Miradas Lejanas e CLACOS/SIGLO XXI (publicação conjunta). Todas estão em fase de publicação e, depois de finalizadas, irão contar com mais de 50 títulos que devem reunir a contribuição de mais de 350 autores de diversos campos sobre o pensamento latino-americano.

A série Trayectorias, na qual se insere a obra sobre Gerónimo de Sierra, reúne os textos mais importantes e representativos de destacados intelectuais latino-americanos e possui, até o momento, as seguintes publicações:

- "Gino Germani: la sociedad en cuestión” (CLACSO/UBA, 2010) organizada por Carolina Mera e Julián Rebón reúne textos emblemáticos deste importante pensador argentino, apresentando sua contribuição na consolidação das ciências sociais, especialmente a sociologia, e na tentativa de explicar as mudanças que a sociedade argentina e, de certa forma, toda a América Latina passaram ao longo do século passado, em torno da noção de modernização e seus impactos econômicos, políticos e sociais;

- “Anibal Quijano: cuestiones y horizontes” (CLACSO, 2014) com a seleção de Danilo Assis Clímaco, discute a obra deste fundamental pensador peruano, procurando demonstrar sua importância na construção de um Pensamento Decolonial, que questiona o lugar periférico e subalterno da América Latina, derivdo da visão eurocêntrica da ciência e do poder;

- "Miguel Soler Roca: educación, resistência y esperanza" (CLACSO, 2014) reúne textos deste pensador uruguaio/catalão sobre as políticas públicas na região, principalmente no campo educacional, discutindo sua visão sobre a educação enquanto processo humano, social e político, e sua relação com o desenvolvimento e os desafios do mundo contemporâneo;

- “Roberto Fernández Retamar: Pensamiento anticolonial de Nuestra América" (CLACSO/CASA DE LAS AMÉRICAS, 2016), que apresenta as contribuições deste importante intelectual cubano que, fundamentando no pensamento martiano, critica a racionalidade instrumental e colonial presente nas leituras sobre a América Latina, questionando a dicotomia barbárie e civilização ou Ocidente e Oriente, e a colonialidade atual, que perpassa todas as dimensões da vida latino-americana e sua inserção no sistema internacional; 
- "Fernando C. Gutiérrez: la construcción social de los derechos y la cuestión social del desarrollo" (CLACSO, 2017), que apresenta as contribuições deste pensador boliviano, que atuou em diversos países, sobre a construção dos direitos e os entraves do desenvolvimento social, analisando como nossas sociedades, instituições e práticas sociais tem silenciado a demanda de amplos setores da população ou apresentado projetos insuficientes para solucionar os verdadeiros problemas latinoamericanos;

- “Eduardo Archetti: Antologia Esencial” (CLACSO, 2017), reunindo trabalhos deste instigante antropólogo argentino, discutindo a cultura argentina e de outras regiões latino-americanas, tanto em sua dimensão rural ou agrária como em relação a construção dos elementos constituintes da nacionalidade, numa perspectiva e antropologia crítica;

- “José Aricó: Dilemas del Marxismo en América Latina” (CLACSO, 2017), que reúne textos deste marxista argentino, demonstrando sua contribuição para a divulgação e a incorporação crítica do pensamento gramsciano na região e suas análises mais recentes sobre a crise, os desafios e as alternativas do pensamento crítico no contexto atual;

- "Franz J. Hinkelammert: La vida o el capital- el grito del sujeto vivo y corporal frente a la ley del mercado" (CLACSO/ALAS, 2017), reunindo trabalhos deste filósofo alemão/latino-americano e sua crítica a centralidade do mercado, no capitalismo contemporâneo, refletindo sobre as tensões entre fetichismo e autonomia e entre dominação e emancipação e como estas tem impactado as sociedades latinoamericanas;

- "Norma Giarracca: Estudios rurales y movimientos sociales: miradas desde el Sur" (CLACSO, 2017), apresentado a trajetória desta importante socióloga argentina e suas contribuições, a partir da sociologia rural, para pensar o campesinato, os movimentos sociais do campo e as transformações recentes do mundo rural, inclusive a expansão do agronegócio e do extrativismo e seus efeitos;

- "Elsie Rockwell: Vivir entre Escuelas: relatos y presencias" (CLACSO, 2018), que reúne trabalhos desta importante educadora mexicana, apontando sua contribuição para a educação dos setores marginalizados que incorpora uma perspectiva etnográfica e histórica do processo educacional, propiciando o desenvolvimento de uma 
perspectiva crítica e emancipadora de indígenas e camponeses e discute, a partir da diversidade escolar do México, o trabalho docente e o cotidiano escolar de comunidades não-tradicionais e que devem incorporar outras formas de conhecimento e escrita;

- "Fernando Martínez Heredia: Pensar en tiempos de Revolución" (CLACSO, 2018), que apresenta a obra deste grande pensador cubano, falecido recentemente, e seu imprescindível trabalho para o desenvolvimento de um marxismo latino-americano efetivamente crítico, criativo e revolucionário, associado ao processo revolucionário cubano, a contribuição de clássicos como Che Guevara e os seus desafios contemporâneos.

O trabalho sobre a obra de Gerónimo de Sierra, se insere na dinâmica da coleção, apresentando, de antemão, duas características compartilhadas por estes autores: por um lado, demonstra a unidade entre a obra (as temáticas e as reflexões) e a dinâmica social e política de seu país e região, produzindo um pensamento que procura estar a serviço da transformação social e da construção de sociedades mais justas e solidárias.

Por outro lado, estas obras demonstram que estes autores procuram associar compromisso e sensibilidade social com rigor intelectual, desenvolvendo um pensamento que possa compreender, em profundidade, as características de suas sociedades, desenvolvendo uma crítica profunda da sociedade realmente existente e apontando, na medida do possível, às alternativas necessárias.

Sendo assim, como o título indica está estruturada em dois eixos que estão interligados e associados: a análise da dinâmica política e social do Uruguai, desde a segunda metade do século XX, e, em seguida de forma complementar, da América Latina, considerando a dinâmica e a análise de temáticas mais recentes associadas, principalmente, a Integração Regional e ao desenvolvimento da Sociologia.

Neste sentido, o primeiro eixo, a análise da dinâmica política e social do Uruguai é composto por quatro partes, reunindo inúmeros trabalhos. Na primeira parte, "El Uruguay batllista y su crisis", são reunidos textos sobre a estrutura social e política do Uruguai, discutindo sua história recente, considerando a consolidação e a crise da democracia neste país derrocada por uma ditadura militar, analisados a partir das noções de 'capitalismo democrático' e 'populismo democrático'. 
A segunda parte, intitulada "Ascenso y consolidación de la dictadura cívicomilitar", analisa os elementos que permitiram a ascensão da ditadura militar uruguaia, discutindo sua especificidade, demonstrando o esgotamento do capitalismo democrático no país e, em seguida, analisa a dinâmica de tal ditadura e o começo de seu esgotamento, econômico e político, no início dos anos 80. A terceira parte, denominada de "La transición democrática: política y Estado", que discutem o complexo processo de transição política, do país e da região, considerando os desafios da redemocratização do Estado e da Sociedade, considerando as distintas posições e grupos políticos, e, em seguida, analisa os impactos do pensamento neoliberal, sua visão elitista e tecnocrática, na reconstrução do país.

A quarta, e última parte, intitulada "Los procesos electorales y su contexto socioeconómico" reúne trabalhos que versam sobre as recentes mudanças políticas no sistema político e de partidos do Uruguai, com a ascensão da Frente Ampla, como principal força de centro-esquerda e, posteriormente, como força eleitoral majoritária e sua atuação no sistema uruguaio, bem como os desafios para sua consolidação.

O segundo eixo do trabalho se fundamenta, em interação com a dinâmica uruguaia, no desenvolvimento de temáticas relacionadas à América Latina e é composta de três partes. A primeira, denominada de "América Latina: países y processos", analisa, como indicado, tanto processos gerais referentes a região nas últimas décadas (como os impasses da redemocratização, os efeitos do neoliberalismo, a crise do desenvolvimento e a emergência de uma nova visão sobre a Integração Regional, tema que será fundamental mais adiante) como a realidade social e política de países específicos, como Cuba, México e Brasil, dentre outros.

A segunda parte, intitulada "Integración regional", apresenta trabalhos que discutem a dinâmica e os desafios do processo de Integração Regional, temática que adquiriu importância crescente na obra do autor, considerando a inserção do Uruguai e suas forças políticas, como o recente processo de ampliação e fortalecimento institucional e político do MERCOSUL, combinado com o ciclo de 'governos progressistas' no Uruguai, Argentina, Brasil, Bolívia, Venezuela e, até certo momento, Paraguai. Constitui-se numa perda analítico a ausência, por razões relacionadas aos limites de prazo para publicação, a ausência de uma análise mais recente, considerando a dinâmica política e a ascensão de novas forças, desmobilizadoras do processo de Integração Regional, em Brasil e Argentina, principalmente. 
Finalmente, a última parte, denominada de "Las ciencias sociales en Uruguay y América Latina", analisa o desenvolvimento das ciências sociais, com ênfase na sociologia, no Uruguai e na América Latina, considerando seu impulso inicial e seu desenvolvimento acadêmico, discutindo as temáticas clássicas (desenvolvimento, modernização, regimes autoritários, globalização, ...) que marcaram sua consolidação. Além disto, discute o processo de profissionalização tardia desta ciência em nossas sociedades e como isto tem afetado a atuação de sociólogos e a relevância desta, submetidos aos desafios do poder crescente dos mercados, inclusive na academia.

Da obra, além dos aspectos já mencionados, outros elementos merecem destaque. Como demonstram os textos, o autor consegue captar, com acerto, a dicotomia entre a unidade e a diversidade que caracterizam a América Latina, principalmente, ao destacar as assimetrias entre os países e a dinâmica política e social das pequenas nações.

Além disto, o trabalho é marcado pela convergência frutífera entre uma abordagem interdisciplinar, com destaque para a sociologia política, e a utilização de múltiplos enfoques metodológicos, enriquecendo e ampliando o escopo analítico. Por fim, vale mencionar que a obra põe em relevo a contribuição de Gerónimo para a área de Estudos Comparados, produzindo uma abordagem que consegue combinar o global e o regional, o regional e o local e uma análise multidimensional da conjuntura para compreender as sociedades latino-americanas, derivada de seu diálogo e atuação em instituições como a CEPAL, ALAS, CLACSO e FOMERCO, dentre outras.

Diante disto, torna-se evidente a importância e a estatura intelectual deste autor, que combina profundidade teórica e compromisso social, como destaca Alberto Riella, no prólogo, ao mencionar que: "En síntesis, su larga trayectoria y su destacada actividad académica lo convierten hoy en una de las figuras más notorias de los estudios latinoamericanos. La compilación de su obra será, sin duda, un gran legado para el pensamiento del continente, y servirá de inspiración para que los actuales y futuros pensadores exploren nuevas reflexiones sobre los grandes problemas de América Latina" (Alberto Riela, 2017, p. 15).

Sendo assim, é possível apontar que a obra, assim como toda a coleção de CLACSO, ao apresentarem trajetórias fundamentais do pensamento latino-americano contemporâneo, torna-se fundamental para o conhecimento da América Latina dos 
problemas recorrentes e seculares que afetam a região (desigualdade, dominação, submissão, silenciamentos,...) e a construção de alternativas, alicerçadas na construção de direitos efetivos, de respeito as culturas e povos originários, de desenvolvimento económico e social, de democracia participativa e inclusiva e justiça social. Boa Leitura!!! 